\title{
Determination of Total Phenolic Content, Analysis of Bioactive Compound Components, and Antioxidant Activity of Ethyl Acetate Seri (Muntingia calabura L.) Leaves from North Sumatera Province, Indonesia
}

\author{
Risanti Febrine Ropita Situmorang ${ }^{1}$, Kasta Gurning ${ }^{2 *}$ (D), Vera Estefania Kaban² ${ }^{2}$, Mastiur Julianti Butar-Butar ${ }^{3}$, \\ Susi Amenta Beru Perangin-Angin ${ }^{3}$ \\ ${ }^{1}$ Department of Health Analyst, Sekolah Tinggi Ilmu Kesehatan Senior Medan, Medan, Indonesia; ${ }^{2}$ Department of Pharmacy, \\ Sekolah Tinggi IImu Kesehatan Senior Medan, Medan, Indonesia; ${ }^{3}$ Department of Midwifery, Sekolah Tinggi IImu Kesehatan \\ Senior Medan, Medan, Indonesia
}

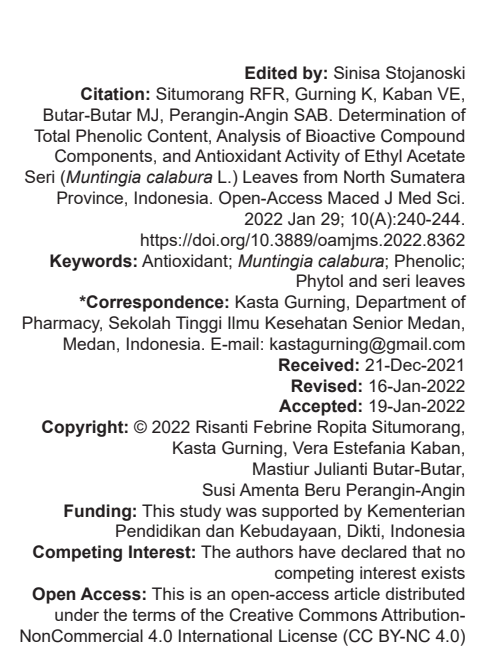

\begin{abstract}
BACKGROUND: Seri (Muntingia calabura L.) leaves are a plant that is often found and have not been used in various treatments even though it is reported to have various groups of bioactive compounds such as phenolic flavonoids, tannins, saponins, steroids, and triterpenoids.

AIM: This study aimed to determine the total phenolic content, antioxidant activity and identify the content of potentia bioactive compounds contained in the ethyl acetate fraction from $M$. calabura leaves.

METHODS: M. calabura L. leaves fraction was carried out by maceration method using ethanol followed by partition starting with $n$-hexane, chloroform, and finally ethyl acetate as solvent. The ethyl acetate fraction was continued for phytochemical screening for the content of bioactive compounds using standard reagents, determination of total phenol content by colorimetric method, determination of antioxidant activity using the DPPH method, and analysis of bioactive compounds using gas chromatography-mass spectroscopy.

RESULTS: The results showed that the ethyl acetate fraction of $M$. calabura leaves was positive for phenolic content which was indicated by the formation of a turquoise color after $5 \% \mathrm{FeCl}_{3}$ reagent was added (in ethanol), phenolic content was $0.0727 \mathrm{mg} \mathrm{GAE} / \mathrm{g}$ dry fraction, indicating antioxidant activity $\left(\mathrm{IC}_{50}\right.$ ) amounted to 54.437 including strong categories as antioxidants and the results of GC-MS analysis obtained various kinds of compounds and it is suspected that compounds that provide potential as antioxidants are phytol.

CONCLUSION: The bioactive compound of ethyl acetate fraction of seri ( $M$. calabura) leaves contained phenolic components and has strong antioxidant activity.
\end{abstract}

\section{Introduction}

Free radicals play many roles in human life. Free radicals in the body are produced from the metabolism of the ATP production process in the mitochondria. In general, the sources of free radicals are divided into reactive oxygen species free radicals and reactive nitrogen species. Low concentrations of free radicals in the body have beneficial roles, but at high concentrations, they can cause oxidative stress and damage cell walls that can trigger the emergence of various chronic and degenerative diseases such as cancer, arthritis, aging, cardiovascular, and neurodegenerative [1], [2]. Minimizing the impact and influence caused by free radicals requires an antioxidant compound. Sources of antioxidant compounds in the body are divided into endogenous antioxidants and exogenous antioxidants. Endogenous is antioxidant compounds produced by the body while exogenous is obtained by the body through consumption of various foods such as vegetables, fruits, nuts, seeds, spices, and oils [3]. One of the potential plants that can be tested for its potency as an antioxidant is seri leaf (Muntingia calabura L.). The content of bioactive compounds contained in $M$. calabura leaves includes phenolics, flavonoids, tannins, triterpenes, saponins, and alkaloids [4], [5], [6]. This plant is widely found in Indonesia and grows and breeds on the side of the road and is widely used as a shade tree. Various groups of bioactive compounds contained in the plant $M$. calabura attracted the attention of researchers to determine the quantitative analysis of bioactive compounds, especially phenolics and tested their pharmacological activities as antioxidants with the 2,2-diphenyl-1dipicrylhydrazil (DPPH) method. The previous studies have screened bioactive compounds from $M$. calabura leaves extracted with ethanol/methanol/n-hexane/ 
ethyl acetate and tested their activity. Research that examines the results of the partitioning of the ethanolic leaf extract of $M$. calabura leaves and then identified the class of compounds and the analysis, especially on the determination of bioactive compounds in a single form, is still very limited. Based on this description, the researchers were interested in determining the phenolic content of the partitioned ethanol extract of $M$. calabura leaves with ethyl acetate, which was followed by testing its antioxidant activity using the DPPH method and identifying bioactive compounds using gas chromatography-mass spectroscopy (GC-MS) as a basis which would later be used in the determination of compounds bioactive in a single form which is potential as an antioxidant.

\section{Materials and Methods}

\section{Materials}

The materials used include ethanol (Merck), chloroform (Merck), n-hexane (Merck), ethyl acetate (Merck), Folin-Ciocalteu, Whatman No 1 filter paper, $\mathrm{Na}_{2} \mathrm{CO}_{3}$ (Merck), standard reagents for phytochemical filtration, acid gallate (Merck), $\mathrm{FeCl}_{3}$ (Merck), methanol (pa), DPPH (Merck), Vitamin C (Merck), and distilled water.

\section{M. calabura sample preparation}

Samples of $M$. calabura leaves were obtained from Namorambe Regency, North Sumatra Province, Indonesia, with fresh and green conditions from fruiting trees. The samples were determined and validated by a botanist with a registration number (No.5107/ MEDA/2020) at the Medanense Herbarium laboratory, Universitas Sumatera Utara. The samples were cleaned with running water, drained, and then dried in a drying cabinet at a temperature of $50^{\circ} \mathrm{C}$. The dry samples were ground using a kinetic blender to obtain simplicia powder. Simplicia powder is placed in a storage container and placed in a botanical laboratory before use.

\section{Extraction of M. calabura leaves bioactive compounds}

M. calabura simplicia powder was extracted by maceration method using ethanol as a solvent at room temperature with occasional stirring with the aim of optimizing the extraction of bioactive compounds for 3 days. Once achieved, then filtered using whatman paper No. 1, so that the liquid M. calabura leaves ethanol extract was obtained. The residue was remacerated 2 times to optimize filtration for 2 days following the previous steps. The ethanol extract of
M. calabura leaves was concentrated using a vacuum rotary evaporator at $55^{\circ} \mathrm{C}$ and a thick extract was obtained. The viscous extract was then made graded partition based on the difference in solvent polarity, starting with separation with $n$-hexane solvent (the purpose of separating non-polar bioactive compounds), chloroform solvent (separation of semi-polar bioactive compounds), and ethyl acetate solvent (separating low polar bioactive compounds). This partition process with the liquid-liquid principle using a separating funnel then obtained the $n$-hexane extract and ethanol extract residue. Then, the ethanol extract residue was partitioned again with chloroform and then with ethyl acetate. For each treatment, the partition was repeated 3 times to maximize the partition of the bioactive compounds contained based on the polarity of the solvent. The ethyl acetate fraction obtained was concentrated using a vacuum rotary evaporator at $55^{\circ} \mathrm{C}$, phytochemical screening, determination of total phenolic content, determination of activity as an antioxidant, and analysis of components of bioactive compounds using GC-MS.

\section{Phytochemical screening}

Phytochemical screening was carried out as the first step in identifying the group of bioactive compounds contained in the ethyl acetate fraction of M. calabura leaves. Phytochemical screening used standard reagents against groups of compounds including flavonoids, alkaloids, saponins, phenolics, tannins, triterpenoids, and steroids [7], [8], [9], [10], [11].

\section{Determination of the group of total phenolic compounds}

Determination of total phenolic compounds using a modified colorimetric method using FolinCiocalteu reagent, adding $\mathrm{Na}_{2} \mathrm{CO}_{3}$ with a concentration of $7 \%$, and measuring its absorbance at a wavelength of $765 \mathrm{~nm}$ by spectrophotometry [12], [13]. Determination of phenolic content using standard gallic acid solution with various concentrations of $50 \mathrm{ppm}, 75 \mathrm{ppm}$, $100 \mathrm{ppm}, 125 \mathrm{ppm}$, and $150 \mathrm{ppm}$ with methanol as solvent. Each of the concentration variations was taken $200 \mu \mathrm{L}$, then added $1 \mathrm{~mL}$ of Folin-Ciocalteu and allowed to stand for $5 \mathrm{~min}$ followed by the addition of $4 \mathrm{~mL}$ of $7 \% \mathrm{Na}_{2} \mathrm{CO}_{3}$ and distilled water up to $10 \mathrm{~mL}$. The solution mixture was incubated for $30 \mathrm{~min}$, then the absorbance was measured at a wavelength of $765 \mathrm{~nm}$. Absorbance measurements were carried out 3 times. The linear regression equation obtained is $y=0.0042 x-0.0468$ with $R^{2}=0.9793$ (Figure 1). Determination of the phenolic content of the ethyl acetate fraction of $M$. calabura leaves followed the same procedure with a concentration of $1000 \mathrm{ppm}$. Phenolic content is expressed in $\mathrm{mg}$ by weight of gallic acid equivalent/g dry extract (mg GAE/g dry fraction). 


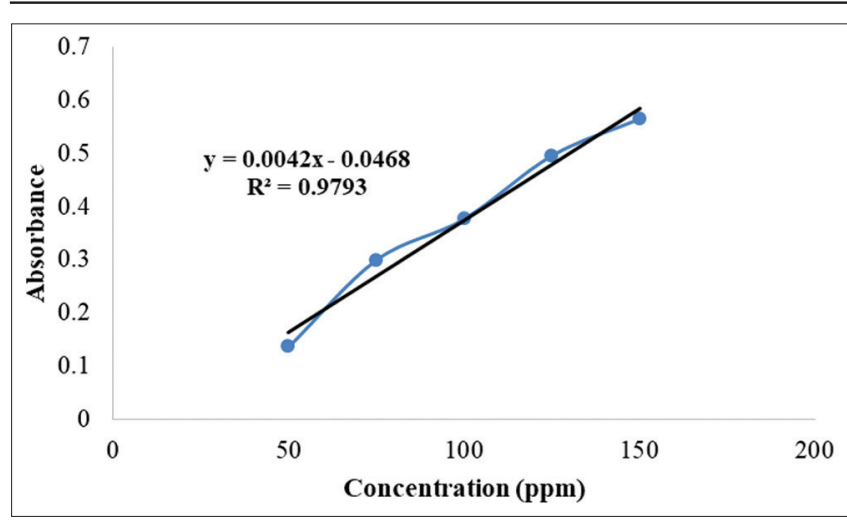

Figure 1: Gallic acid standard solution curve

\section{Determination of antioxidant activity}

The ethyl acetate fraction of $M$. calabura leaves was carried out using the modified DPPH method. Variations in the concentration of $M$. calabura leaves ethyl acetate fraction used 50 ppm, 100 ppm, $150 \mathrm{ppm}, 200 \mathrm{ppm}$, and $250 \mathrm{ppm}$. The volume of each concentration used was $500 \mu \mathrm{L}$, then $1 \mathrm{~mL}$ of $0.4 \mathrm{mM}$ DPPH was added and ethanol was added up to $5 \mathrm{~mL}$. The mixture was incubated for $30 \mathrm{~min}$. After the incubation time was reached, the absorbance was measured at $517 \mathrm{~nm}$ [14]. The same procedure was carried out for Vitamin $\mathrm{C}$ as a positive control with variations in concentrations of $6.5 \mathrm{ppm}, 7.0 \mathrm{ppm}$, $7.5 \mathrm{ppm}, 8.0 \mathrm{ppm}$, and $8.5 \mathrm{ppm}$. Negative control was carried out by adding $1 \mathrm{~mL}$ of $0.4 \mathrm{mM} \mathrm{DPPH}$ and adding ethanol to $5 \mathrm{~mL}$. Absorbance measurements were carried out 3 times. Determination of free radical inhibition by the following equation:

$$
\text { Inhibition }(\%)=\left[\frac{{ }^{A} \text { Blank }-{ }^{A} \text { Sample }}{{ }^{A} \text { Blank }}\right] \times 100
$$

Linear regression equation in determining the value of antioxidant activity conducted by plotting the percentage of inhibition curve against the concentration variations to obtain a linear regression equation. The obtained linear regression equation was used to calculate the value of antioxidant activity inhibitory concentration $50\left(\mathrm{IC}_{50}\right)$. The $\mathrm{IC}_{50}$ value is expressed as the ability of the antioxidant activity of the ethyl acetate fraction leaves to reduce free radicals originating from $\mathrm{DPPH}$ by $50 \%$ of the initial concentration.

\section{Component analysis of bioactive compounds by GC-MS}

The viscous fraction of $M$. calabura leaves ethyl acetate was analyzed using Thermo Scientific Trace 1310 Gas Chromatograph with column HP-5MS Ul operating at an electron collision energy of $70 \mathrm{eV}$ and ISQLT Quadrupole Mass Spectrometry specifications. The carrier gas used is helium with an injection volume of $0.5 \mu \mathrm{L}$ with a splitless injection temperature of $300^{\circ} \mathrm{C}$, an ion source temperature of $280^{\circ} \mathrm{C}$ with a mooring time of 5 min starting with a temperature of $100-300^{\circ} \mathrm{C}$ with a temperature change rate of $5^{\circ} \mathrm{C}$. The identified active compounds were compared with peak retention times with the Chromeleon smilarity library MS instrument.

\section{Results and Discussion}

\section{Phytochemical screening}

Phytochemical screening aims to obtain initial information on groups of bioactive compounds identified using standard reagents (Table 1). The results of phytochemical screening showed positive groups of flavonoid compounds, saponins, tannins, triterpenoids/steroids, and phenolics. The phenolic group was indicated by the formation of a green or bluegreen color, flavonoids are indicated by the formation of a pink color, saponins are indicated by the formation of foam, tannins are indicated by the loss of bromine color, triterpenoids are indicated by the formation of a green color, and steroids are indicated by a red color. However, the ethyl acetate fraction leaves of $M$. calabura negative contained alkaloids.

\section{Table 1: Results of phytochemical screening}

\begin{tabular}{llll}
\hline S. No. & Compound Group & Reagents & Results \\
\hline 1. & Alkaloids & Dragendorf's & - \\
& & Mayer & - \\
& & Liebermann-Bouchard & - \\
2. & Phenolics & $\mathrm{FeCl}_{3} 5 \%$ (at ethanol) & + \\
3. & Flavonoids & Shinoda test & + \\
4. & Saponins & Foaming test $^{-}$ & + \\
5. & Tannins & $\mathrm{FeCl}_{3} 1 \%$ & + \\
6. & Triterpenoids/steroids & Liebermann-Bouchard & + \\
\hline
\end{tabular}

\section{Determination of total phenolic content}

The total phenolic content of the ethyl acetate fraction of $M$. calabura leaves from the linear regression equation was obtained $y=0.0042 x-0.0468$ with $R^{2}$ $=0.9793$ from $0.0727 \mathrm{mg}$ GAE $/ \mathrm{g}$ dry fraction. The quantitative results of this group of phenolic compounds are in line with the phytochemical screening data using $\mathrm{FeCl}_{3}$. Phenolic content is reported to show activity as an antioxidant, anticancer, anti-inflammatory, antibacterial, and xanthine oxidase inhibitor [15].

\section{Antioxidant activity}

Antioxidant activity was determined by the DPPH method using ethanol as a solvent and measured at a maximum wavelength of $517 \mathrm{~nm} \mathrm{DPPH}$. The selection of the DPPH method in determining antioxidant activity is based on better sensitivity, relatively low cost, and simple and fast processing. The antioxidant activity value of the ethyl acetate fraction of $M$. calabura leaves expressed in $\mathrm{IC}_{50}$ from the linear regression equation $y=0.2479 x+36.505 ; R^{2}=0.9859$ 


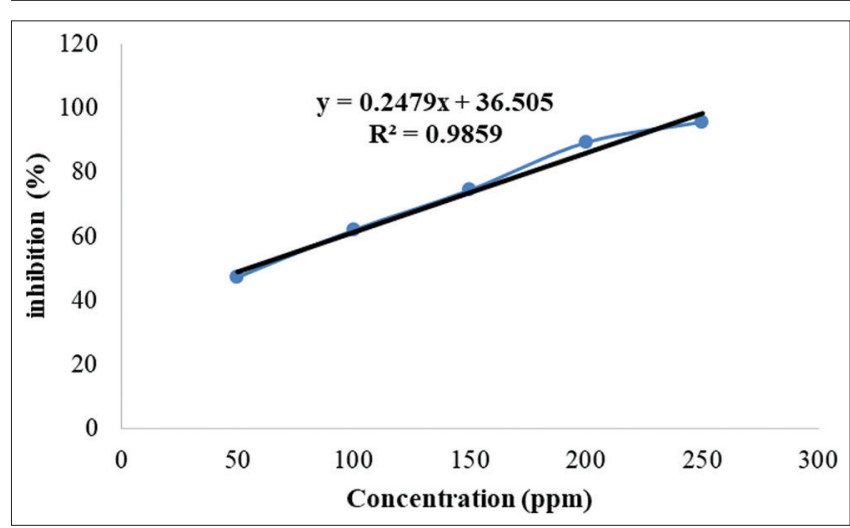

Figure 2: Test curve for the antioxidant activity

(Figure 2) of 54,437 in the strong category and $\mathrm{IC}_{50}$ for Vitamin $\mathrm{C}$ of 1.657 in the very strong category. The antioxidant activity value of the strong category of ethyl acetate fraction is supported by its ability to release protons to stabilize free radicals from $\mathrm{DPPH}$ to DPPH-H so as to produce neutral conditions [2]. These results are in line with the presence of phenolic content which is responsible for providing antioxidant activity.

\section{compounds}

\section{GC-MS analysis activity of bioactive}

Analysis using GC-MS showed the content of bioactive compounds in the ethyl acetate fraction of M. calabura leaves. The results of the GC-MS analysis are shown in Figure 3.

The GC-MS chromatogram showed that there were 16 types of bioactive compounds with the largest retention time span of $4.0-45.0 \mathrm{~min}$. The components with the largest percentage reported that there are five bioactive compounds presented in Table 2.

The largest bioactive compound contained was phytol. Phytol is reported to have potential activity as antimicrobial, insulin enhancing, anticancer, antidiuretic [16], anti-inflammatory [17], and antioxidant [18], [19], [20]. Researchers suspect that the content of these compounds provides potential activity as antioxidants, but there are still wide opportunities for other compounds that provide synergism as antioxidants.

\section{Conclusion}

The ethyl acetate fraction of $M$. calabura leaves has $0.0727 \mathrm{mg}$ phenolic content GAE/g dry fraction and has strong antioxidant activity. The results of the analysis by GC-MS showed the potential of phytol as an antioxidant.

\section{Acknowledgments}

We take this opportunity to thank the Kementerian Pendidikan dan Kebudayaan, Dikti, Indonesia, for the contract 247/LL1/PG/2021 in 2021

Table 2: Analysis of bioactive compounds with GC-MS

\begin{tabular}{|c|c|c|c|c|c|}
\hline S. No. & Compound name & Molecular formula & $\mathrm{T}_{\mathrm{R}}$ (menit) & $\%$ area & Evidence peak \\
\hline 1. & Phytol & $\mathrm{C}_{20} \mathrm{H}_{40} \mathrm{O}$ & 35.33 & 34.84 & 10 \\
\hline 2. & 9,12,15-Octadecatrienoic acid, methyl ester, $(Z, Z, Z)$ & $\mathrm{C}_{10} \mathrm{H}_{32} \mathrm{O}_{2}$ & 35.11 & 3332 & 9 \\
\hline 3. & Hexadecanoic acid, methyl ester & $\mathrm{C}_{17}^{19} \mathrm{H}_{34} \mathrm{O}_{2}^{2}$ & 31.79 & 17.77 & 7 \\
\hline 4. & 17-Octadecynoic acid, methyl ester & $\mathrm{C}_{19}^{11} \mathrm{H}_{34}^{34} \mathrm{O}_{2}^{2}$ & 35.55 & 3.70 & 11 \\
\hline 5. & 7-Methyl-Z-tetradecen-1-ol acetate & $\mathrm{C}_{17}^{19} \mathrm{H}_{32} \mathrm{O}_{2}$ & 23.43 & 3.39 & 8 \\
\hline
\end{tabular}

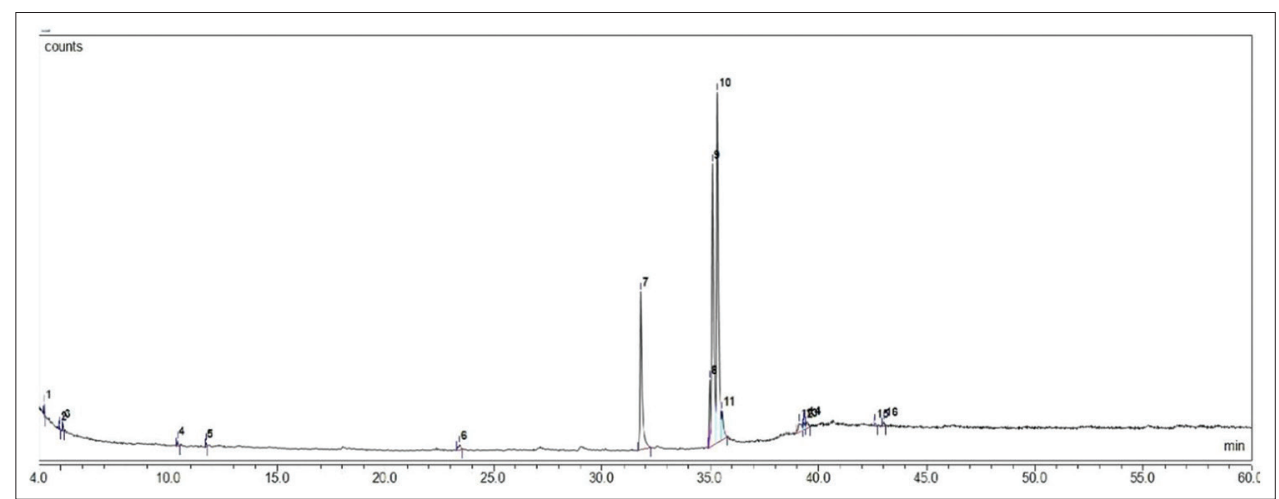

Figure 3: Gas chromatography-mass spectroscopy chromatogram Muntingia calabura leaves ethyl acetate fraction 
and the opportunity to obtain research funds for the novice lecturer scheme to increase the ability of lecturers in research and publication.

\section{References}

1. Oliveira YP, Ponttes-de-Carvalho LC, Couto RD, NoronhaDutra AA. Oxidative stress in sepsis possible production of free radicals through an erythrocyte-mediated positive feedback mechanism. Braz J Infect Dis. 2017;21(1):19-26. https://doi. org/10.1016/j.bjid.2016.11.004

PMid:27916603

2. Gurning K, Haryadi W, Harjono S. Isolation and characterization of antioxidant compounds of Bangun-Bangun (Coleus amboinicus, L.) Leaves from North Sumatera Indonesia. Rasayan J Chem. 2021;14(1):248-53. https://doi.org/10.31788/ RJC.2021.1416077

3. Rizzo AM, Berselli P, Zava S, Montorfano G, Negroni M, Corsetto P, Berra B. Endogenous antioxidants and radical scavengers. Adv Exp Med Biol. 2010;698:52-67. https://doi. org/10.1007/978-1-4419-7347-4_5

PMid:21520703

4. Yusof MI, Salleh MZ, Kek TL, Ahmat N, Azmin NF, Zakaria ZA. activity-guided isolation of bioactive constituents with antinociceptive activity from Muntingia calabura L. leaves using the formalin test. Evid Based Complement Altern Med. 2013;2013:715074. https://doi.org/10.1155/2013/715074 PMid:24348716

5. Mahmood ND, Nasir NL, Rofiee MS, Tohid SF, Ching SM, Teh LK, et al. Muntingia calabura: A review of its traditional uses, chemical properties, and pharmacological observations. Pharm Biol. 2014;52(12):1598-623. https://doi.org/10.3109/13880209. 2014.908397

PMid:25068675

6. Buhian WP, Rubio RO, Valle DL Jr., Martin-Puzon JJ. Bioactive metabolite profiles and antimicrobial activity of ethanolic extracts from Muntingia calabura L. leaves and stems. Asian Pac J Trop Biomed. 2016;6(8):682-5. https://doi.org/10.1016/j. apjtb.2016.06.006

7. Gul R, Jan SU, Faridullah S, Sherani S, Jahan N. Preliminary phytochemical screening, quantitative analysis of alkaloids, and antioxidant activity of crude plant extracts from ephedra intermedia indigenous to balochistan. Sci World J. 2017;2017:5873648. https://doi.org/10.1155/2017/5873648

8. Rao US, Abdurrazak M, Mohd KS. Phytochemical screening, total flavonoid and phenolic content assays of various solven extracts of tepal of Musa paradisiaca. Malaysian J Anal Sci. 2016;20(5):1181-90. http://dx.doi.org/10.17576/ mjas-2016-2005-25

9. Mahmood N, Nazir R, Khan M, Iqbal R, Adnan M, Ullah M, et al. Phytochemical screening, antibacterial activity and heavy metal analysis of ethnomedicinal recipes and their sources used against infectious diseases. Plants. 2019;8(11):454. https://doi. org/10.3390/plants8110454

PMid:31717808

10. Syahrina S, Asfianti V, Gurning K, Iksen I. Phytochemical screening and anti-hyperuricemia activity test in vivo of ethanolic extract of shallot (Allium cepa L.) Skin. Borneo J Pharm. 2020;3(3):146-51. https://doi.org/10.33084/bjop.v3i3.1365

11. Gurning K, Boangmanalu R, Simanjuntak HA, Singarimbun N, Rahmiati R, Lestari W. Identification of secondary metabolites and antidiarrheal activity of pirdot leaves ethanol extract (Saurauia vulcani Korth.) from West Papapk, North Sumatera Province, Indonesia. Rasayan J Chem. 2020;13(4):2385-9. https://doi.org/10.31788/RJC.2020.1345984

12. Pochapski MT, Fosquiera EC, Esmerino LA, Santos EB, Farago PV, Santos FA, et al. Phytochemical screening, antioxidant, and antimicrobial activities of the crude leaves extract from Ipomoea batatas (L.) Lam. Pharmacogn Mag. 2011;7(26):165-70. https://doi.org/10.4103/0973-1296.80682 PMid:21716926

13. Liaudanskas M, Zymone $\mathrm{K}$, Viskelis $\mathrm{J}$, Klevinkas A, Janullis V. Determination of the phenolic composition and antioxidant activity of pear extracts. J Chem. 2017;2017:7856521. https:// doi.org/10.1155/2017/7856521

14. Naz R, Bano A. Phytochemical screening, antioxidants and antimicrobial potential of lantana camara in different solvents. Asian Pacific J Trop Dis. 2013;3(6):480-6. https://doi. org/10.1016/S2222-1808(13)60104-8

15. Maria R, Shirley M, Xavier C, Jaime S, David V, Rosa S, et al Preliminary phytochemical screening, total phenolic content and antibacterial activity of thirteen native species from guayas province ecuador. J King Saud Univ Sci. 2018;30(4):500-5. https://doi.org/10.1016/j.jksus.2017.03.009

16. Pratama OA, Tunjung WAS, Stikno, Daryono BS. Bioactive compound profile of melon leaf extract (Cucumis melo L. Hikapel) Infected by Downy Mildew. Biodiversitas. 2019;20(11):3448-53. https://doi.org/10.13057/biodiv/d201143

17. Vats S, Gupta T. Evaluation of bioactive compounds and antioxidant potential of hydroethanolic extract of Moringa oleifera Lam. from Rajasthan, India. Pysiol Mol Biol of Plants. 2017;23(1):239-48. https://doi.org/10.1007/s12298-016-0407-6 PMid:28250599

18. Casuga FP, Castillo AL, Corpuz MJ. GC-MS analysis of bioactive compounds present in different extracts of an endemic plant Broussonetia luzonica (Blanco) (Moraceae) Leaves. Asian Pac J Trop Biomed. 2016;6(11):957-61. https://doi.org/10.1016/j. apjtb.2016.08.015

19. Thakor P, Mehta JB, Patel RR, Patel DD, Subramanian RB, Thakkar VR. Extraction and purification of phytol from Abutilon indicum: Cytotoxic and apoptotic activity. RSC Adv. 2016;6(54):48336-45. https://doi.org/10.1039/C5RA24464A

20. Ishtiaq S, Hanif U, Shaheen S, Bahadur S, Liaqat I, Awan UF, et al. Antioxidant potential and chemical characterization of bioactive compounds from a medicinal plant Colebrookea oppositifolia Sm. An Acad Bras Cienc. 2020;92(2):1-15. https:// doi.org/10.1590/0001-3765202020190387 